\title{
RAPID GENERATION OF FLOOD MAPS USING DUAL-POLARIMETRIC SYNTHETIC APERTURE RADAR IMAGERY
}

\author{
MinJeong $J^{1}$, Batuhan Osmanoglu ${ }^{2}$ \\ ${ }^{1}$ USRA, NASA-GSFC, Greenbelt, MD, 20771 USA - minjeong.jo@nasa.gov \\ 2 NASA-GSFC, Greenbelt, MD, 20771 USA - batuhan.osmanoglu@nasa.gov
}

\begin{abstract}
Rapid generation of synthetic aperture radar (SAR) based flood extent and flood depth maps provide valuable data in disaster response efforts. We present a simple but powerful method using dualpolarimetric SAR imagery. A RGB false-color map is generated using pre- and post-flooding imagery, allowing operators to distinguish between existing standing water in pre-flooding data and recently flooded areas. This method works very well in areas of standing water, while large omission errors can be seen in urban areas due to the double-bounce effect. A flood depth map is also estimated by using an external DEM. Compared with FEMA flood product, flood water depth from the proposed method showed low bias with small dispersion. This automatic flood mapping system will contribute to the rapid assessment for disaster relief efforts.
\end{abstract}

Index Terms- Floods, Dual-polarimetric SAR, Flood depth map, Flood extent map

\section{INTRODUCTION}

According to the International Disaster Charter activations since 2000 , floods are the most frequent type of disasters around the world (Bally and Papadopoulou, 2017). In 2017, there were 44 charter activations, and $39 \%$ of their work were associated with flood event. Also, $27 \%$ of their actions was for oceanic storms which include hurricanes and typhoons. All of this means that flood is one of the most important things that we have to care for disaster relief.

The main purpose of this study is to provide flood maps in a short time in order to help urgent decisionmaking right after the flooding event. Optical satellites have been used to make flood maps, but frequently they don't work well in certain weather conditions. SAR imagery, meanwhile, has strong advantage in terms of weather conditions, therefore, radar data can support of replace the products from optical imagery.

Here, we propose a simple way of monitoring floods events based on dual-polarimetric SAR imagery. This will be able to provide both flood extent maps and flood water depth maps. The flood products from the proposed method can be used for the crossvalidation of those from other existing methods (Chung et al., 2015; Twele et al., 2016; Zhang et al., 2017).

\section{METHOD}

\subsection{RGB Color Map}

Proposed method relies on the differences in physical interaction between standing water and the rough land surface. Due to the specular reflection over standing water the returned signal strength to the side-looking antenna is minimal in all polarizations as long as the water surface is still. On the other hand, the rough surface has a larger signal return to the radar. Based on this, we propose a RGB false-colour composite of pre- and post-flood imagery as:
R: $20 * \log 10\left(\left|\mathrm{VV}_{\text {post }}\right|\right)$
G: $20 * \log 10\left(\left|\mathrm{VH}_{\text {post }}\right|\right)$
B: $20 * \log 10\left(0.5 *\left(\left|\mathrm{VV}_{\text {pre }}\right|+\left|\mathrm{VH}_{\text {pre }}\right|\right)\right)$

Where |.| denotes absolute value, and $20 * \log 10$ is the operation to convert to $\mathrm{dB}$ scale. This composition generates an easy to interpret colour image, where existing water areas appear in black, post-event flooded areas appear in blue, and urban to rural areas vary from red to green. Fig. 1 shows the procedure of generating a false color composition map using dual- 


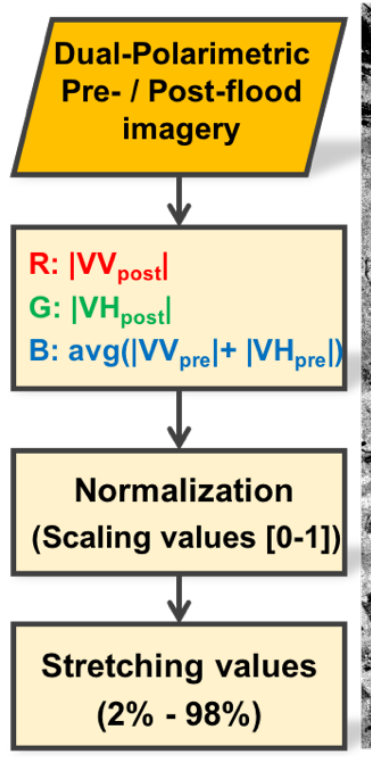

$(2 \%-98 \%)$

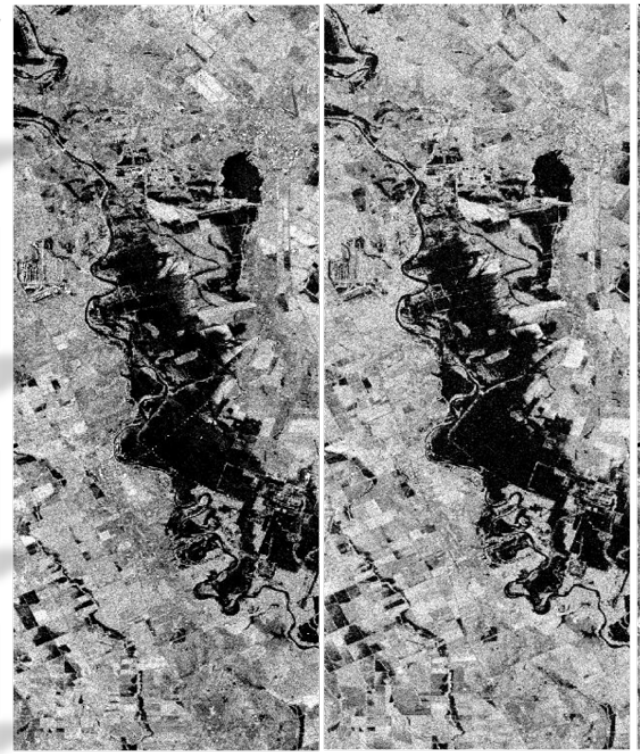

(a) (b)

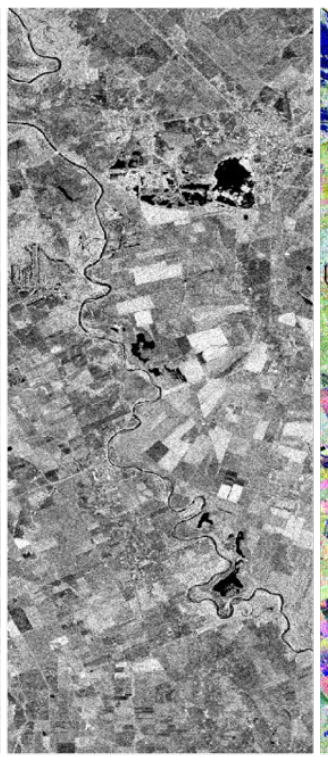

(c)

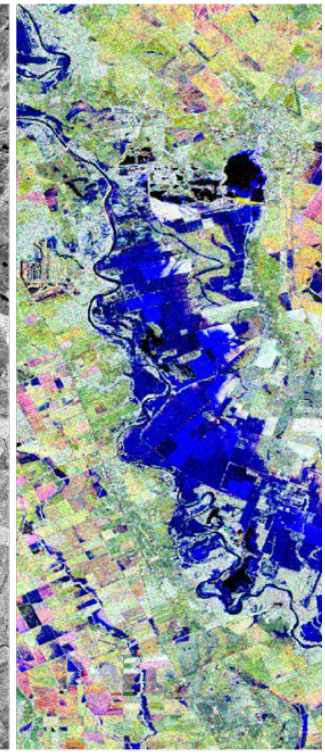

(d)

Fig 1. False color map generation for flood monitoring using dual-polarimetric SAR imagery. (a) |VV-post|, (b) |VH-post|, (c) $\operatorname{avg}(\mid \mathrm{VV}$-pre $|+| \mathrm{VH}-$ pre $\mid)$, (d) RGB color composition map.

polarimetric SAR data set. After assigning values to each bands, we apply scaling and stretching process for normalization. If there is a flooding between two acquisitions, we can detect signal loss in flooded areas. This intensity difference between pre- and post-imagery appears blue in the false color map (Fig. 1(d)).

\subsection{Flood Depth Estimation}

While the false color maps are useful in rapid response as they highlight the flooded areas, they do not provide information of the flood depth. For quantitative assessment of floods, we need to generate flood depth maps.

Figure 2 shows the processing steps of estimating flood water depth using an external DEM. Once we generate the false color composition map, the flooded pixels are extracted by thresholding with a statistical criteria. After that, we apply morphological filter to make water groups. We apply sieving filter as well in order to exclude very small particle. For each water bodies, we need to estimate the water surface height $\left(D E M_{\text {interp }}\right)$. In our study, we obtained the water surface height by interpolating boundary values of each water bodies. Then the flood depth can be estimated as:

$$
H_{F W D, i}=\max \left(0, D E M_{\text {interp }}-D E M_{i}\right)
$$

where $D E M_{i}$ is the elevation for each pixel in the connected water body, and $D E M_{\text {interp }}$ is the water surface height obtained by interpolation.

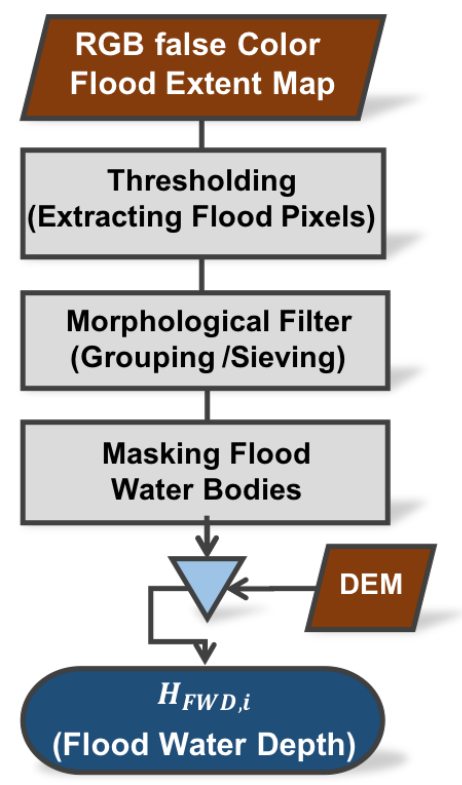

Fig 2. Flow chart for flood depth estimation 


\section{RESULT}

We applied the proposed method for flooded areas near Houston, TX, due to the Hurricane Harvey. The pre- and post- imagery was acquired on August 18 and August 30, 2017, respectively, from the descending orbit. Inundated areas were identified in blue due to the significant change of amplitude between pre- and post- imagery (Fig 1(d)). We also generated flood water depth map using a few external DEM with different spatial resolution.

In order to validate flood extent and flood water depth maps obtained from this study, we compared our result with the flood map provided from FEMA and MODIS flood product (NRT Global Flood Mapping, 2017). FEMA map was generated to show the maximum scenario of flood extent and the flood water height based on NED 1/9 arc-sec DEM and field measurements, such as river gauges, and flood reports by FEMA response personnel (Hurricane Harvey Mitigation portfolio, 2017).

Table 1 shows the comparison results of flooded extent from each products. One rural and one urban area samples were selected for the validation. By the comparison with FEMA map, we confirmed that there are large omission errors, while commission errors were negligible over the entire map. Especially, it is difficult to detect the flood in urban areas from the proposed method. We presumed that the main reason of underestimation for flooded urban areas is dominant double-bounce effect from man-made structures.

\begin{tabular}{|c|c|c|}
\hline \multicolumn{3}{|c|}{ FEMA Flood Map } \\
\hline & $\begin{array}{c}\text { Rural } \\
(\%)\end{array}$ & $\begin{array}{c}\text { Urban } \\
(\%)\end{array}$ \\
\hline $\begin{array}{c}\text { Common Flooded/Non- } \\
\text { flooded Area }\end{array}$ & 71.4 & 43.6 \\
Only Flooded from FEMA & 23.3 & 56.1 \\
Only Flooded from Sentinel-1 & 5.3 & 0.3 \\
\hline \multicolumn{2}{|c|}{ MODIS Flood Map Product } \\
\hline \multicolumn{2}{|c|}{ Rural } & Urban \\
$(\%)$ & $(\%)$ \\
\hline Common Flooded/Non- & 87.8 & 98.8 \\
flooded Area & 5.4 & 0.0 \\
Only Flooded from MODIS & 6.8 & 1.2 \\
\hline
\end{tabular}

Table 1. Comparison results of flood extent against FEMA and MODIS maps
MODIS flood map showed higher agreement with our result than FEMA map. However, both MODIS and our products are only effective in non-urban areas.

For common flooded areas, we estimated water depth difference between FEMA map and our result (Fig 3). The proposed method resulted in underestimations from the products with NED DEM as can be seen in Fig 3(b) an 3(c). These discrepancies can be introduced from the inappropriate interpolation of the water bodies. Thus, we are trying to find the optimal way to interpolate the water bodies to get the accurate water surface height.
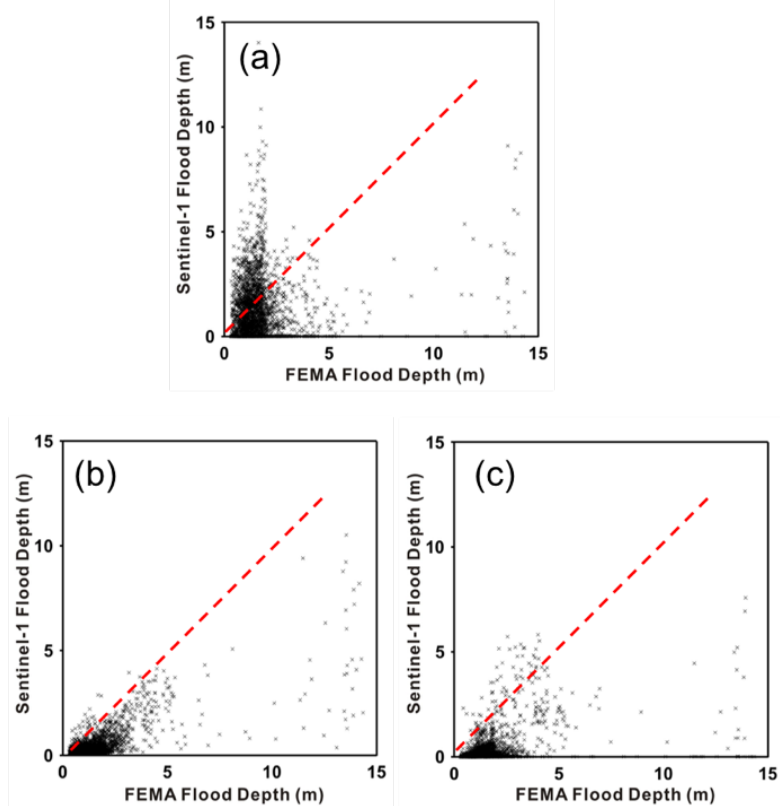

Fig 3. Flood depth difference between FEMA and Sentinel products generated from (a) SRTM 3 arc-sec (b) NED 1/9 $\operatorname{arc}-\sec (c)$ NED 1/3 arc-sec.

\section{CONCLUSION}

We demonstrated a simple flood mapping technique. The proposed method results in generation of easy to interpret false-colour images as well as identifying a process-flow to estimate flood water depth. This will contribute to the rapid assessment for disaster relief efforts. 


\section{ACKNOWLEDGEMENT}

We would like to acknowledge our colleagues at SPoRT Marshall and their collaborators at FEMA. We also acknowledge Lori Schultz (NASA MSFC) for her assistance.

\section{REFERENCES}

Bally, P. and Papadopoulou, T., 2017. The 16th annual report: International Charter "Space and Major Disasters, pp. 17-22.

Chung, H.-W., Liu, C.-C., Cheng, I.-F., Lee, Y.-R., Shieh, M.-C., 2015. Rapid Response to a TyphoonInduced Flood with an SAR-Derived Map of Inundated Areas: Case Study and Validation. Remote Sensing, 7, pp. 11954-11973.

FEMA GeoPlatform, 2017. Hurricane Harvey Mitigation Portfolio, fema.maps.arcgis.com (09 April 2018)

NASA Goddard's Hydrology Laboratory, 2017. Near Real Time (NRT) Global Flood Mapping MODIS Flood Water (MFW) Product, https://floodmap.modaps.eosdis.nasa.gov/ (09 April 2018)

Twele, A., Cao, W., Plank, S., Martinis, S., 2016. Sentinel-1-based flood mapping: a fully automated processing chain. International Journal of Remote Sensing, 37(13), pp. 2990-3004.

Zhang, B., Koirala, R., Oliver-Cabrera, T., Wdowinski, S., Osmanoglu, B., 2017. Mapping the Extent and Magnitude of Severe Flooding Induced by Hurricanes Harvey, Irma, and Maria with Sentinel-1 SAR and InSAR Observations. American Geophysical Union Fall Meeting 2017. 